\title{
Using Community Radios as a Tool for Development
}

Ngugi PK*

Jkuat University, Juja, Kenya

\begin{abstract}
The purpose of this study is to determine to what extent the growth of community radios have changed the lives of ordinary people in Kenya and globally; in particular the illiterate, the urban and rural poor as well as other marginalized groups. The Kenyan Demographic and Health Survey of 2003 estimated that $60 \%$ of men and $71 \%$ of women in Kenya have only gone up to the primary school level of education (Government of Kenya, 2003). Robb asserted in his study that, "I choose to focus on radio because as a technology, it is perhaps the most suitable for community media. Unlike television, it does not require extensive broadcast facilities. Nor does it necessitate the cadre of equipment or the level of capital investment that television requires. Unlike print media, community radio does not require literacy for consumption. Lastly, $99 \%$ of American homes have at least one radio, a greater percentage than read daily newspapers $(55 \%)$ have personal computers $(51 \%)$ or subscribe to cable television $(68 \%)$ (Media Management Center, 2007). Radio remains an accessible and inexpensive form of community media". The historical philosophy of community radios is to use this medium as the voice of the voiceless and the mouthpiece of the oppressed people, or by communities that have not been served by conventional communication structures. It should promote development at the grassroots and bring about positive change in a community's living conditions and environment through dissemination of information and promotion of community dialogue through radio debates and dialogue via phone call ins, SMS and even through social media. The thesis of this paper is that community radios are playing significant roles in livelihood improvement especially for people with no other access to mainstream media.
\end{abstract}

Keywords: Community radio; UNESCO; Broadcasting

Abbreviations: OSIEA: Open Society Institute for East Africa; KCOMNET: Kenya Community Media Network; AMARC: World Association of Community Broadcasters; ENA: Eco News Africa

\section{Introduction}

It is the aim of this paper to determine to what extent the community radio broadcasting has had an impact on the lives of ordinary Kenyans and the rest of the world; in particular the marginalized groups. Longman English Dictionary online defines impact as having an important or noticeable effect on someone or something. According to Crookes and Vittet-Philippe "the problem facing the communications analyst is not whether or not a new medium has had an impact - but precisely what has been its specific impact". Jean Fairbairn and Doreen Rukaria 2011(OSIEA), internationally, there is general agreement on four principles that are seen as pillars of community broadcasting. These are community ownership and control, community service, community participation and a non-profit business model. AMARC members have reached an agreement that community broadcasting is local, nonprofit, participatory broadcasting with a development agenda. Local means generally low transmission capacity within a limited geographic area to enable the audience to participate actively in their community broadcaster. It is also to ensure relevance to local community and to decrease competition with the national public broadcaster and private commercial broadcasters. But, special measures may be taken if the community broadcaster is serving a community that is geographically widespread. Non-profit motive means while community stations may adopt commercial approaches to financing and become commercially successful (sustainable), these profits go back into the community broadcaster or into development projects/programmes around the community broadcaster.

Participation here is at all levels namely ownership, management (through representative local management committees) and production. And special measures are often taken to ensure that those who are historically disadvantaged or marginalized within that community, for example, women, physically challenged can participate in full as well. The BBC World Service Trust believes that community media in Kenya can and will be an important part of the media to give a voice to marginalized communities, promote good governance at local level and help building peace after the post-election violence. Governments in the past have hesitated to promote community media amidst concerns it could exacerbate social and ethnic tension. The Kenya National Commission on Human Rights summarized the role of the vernacular media in the post-election violence as follows "The media and particularly local language media, influenced or facilitated the influencing of communities to hate or to be violent against other communities.

Radio stations broadcasting in Kalenjin languages as well as in the Kikuyu language were culpable in this respect. Live phone-in programmes were particularly notorious for disseminating negative ethnic stereotypes, cultural chauvinism and the peddling of sheer untruths about the political situation or individual politicians."

Jean Fairbairn and Doreen Rukaria 2011(OSIEA), also observes that community radio stations in Kenya do not perceive themselves as being part of a distinct broadcasting sector, with its own values, ethics, practices and role. A 2006 survey of media across Africa by the BBC World Service Trust found serious weaknesses and failures in both the public and private radio sectors in Kenya. The same study also concluded that in order to make ends meet they operate more like a

*Corresponding author: Ngugi PK, Jkuat University, Juja, Kenya, Tel: +254 020 28500; E-mail: ngugi.leoking@gmail.com

Received September 06, 2014; Accepted June 26, 2015; Published June 30, 2015

Citation: Ngugi PK (2015) Using Community Radios as a Tool for Development. J Mass Communicat Journalism 5: 263. doi:10.4172/2165-7912.1000263

Copyright: () 2015 Ngugi PK. This is an open-access article distributed under the terms of the Creative Commons Attribution License, which permits unrestricted use, distribution, and reproduction in any medium, provided the original author and source are credited. 
private station in order to gain audience and advertising revenue and was falling short with respect to its public service mandate.

The confusion between commercial and community radio stations is problematic on a number of levels. There are fears that it is being used expediently by those with an interest in closing down the space that is slowly opening up for independent radio. The exclusion of minority groups in programming is problematic in a society where there is ethnic conflict. It also counters the spirit of the legal and regulatory framework, which emphasizes close to their communities, community radio stations are in an excellent position to promote peace between different factions within communities. However, most of the stations said they avoided politics, in reaction to the violence of 2008. For example, Mwanedu FM, a commercial local language station broadcasting from the market town of Voi in Coast Province, Jean and Rukaria note describes itself as a community station and sees itself as serving the Taita community. It broadcasts in the Taita language and a little English and Kiswahili (the national languages).

However, it does not broadcast in Sagalla, although there is a relatively large Sagalla speaking community, who would benefit from programming, living only a few kilometers. Most of the stations have a strong relationship with their local area MP in some cases, the MP was credited with initiating the station. Most had also received funding from the CDFeg.Kangema FM and Radio Maendeleo. At most of the stations, community participation in programming is extremely limited in some cases restricted to call-ins.

\section{Theoretical and Conceptual Foundations}

Peter Mhagama posits studies about development were heavily dominated by modernization theory which applied insights from communication models to address the shortcomings of development and modernization in Third World countries [1]. The concept of modernization refers to the "fundamental proposition that people in traditional societies should adopt the characteristics of modern societies in order to modernize their social, political and economic institutions." This theory saw the problems of the Third World as emanating from lack of information and traditional cultural practices that hindered development. The remedy to these problems was communication. The modernization paradigm dominated intellectual thinking from around 1945 to 1965 and communication played a crucial role within it. Daniel Lerner and Wilber Schramm theorized that communication was the transmission of information from the Western World to the Third World. They had a strong belief that if traditional societies were exposed to the mass media, they would also be exposed to modern western attitudes which would make them change.

\section{Diffusion of innovation theory}

Everret Rogers developed the diffusion of innovations theory as another communication model of modernization. "Modernization here is conceived as a process of diffusion where individuals move from a traditional way of life to a different, more technically developed and more rapidly changing way of life."

In this model an innovation, which is a new idea or practice, is communicated through certain media over time among members of a social group with the aim of changing their way of thinking or doing things. The model sees development as a type of social change in which new ideas are introduced into a social system to improve agriculture, health, education and politics. Rogers perceive development communication as a "process by which an idea is transferred from a source to a receiver with the intent to change his behavior. Usually the source wants to alter the receiver's knowledge of some idea, create or change his attitude toward the idea, or persuade him to adopt the idea as part of his regular behavior." This model worked on the premise that new ideas diffuse over time according to individuals' stages. $\mathrm{He}$ distinguished five different stages in the diffusion process through which an individual goes in the adoption of innovations: awareness, interest, evaluation, trial and adoption or rejection. The role of the mass media manifests in the first stage which is awareness where the traditional society is exposed to the new ideas or innovations.

The early adopters set an example for the others to follow suit, allowing development to trickle down to the rest of the society. The slow ones continue to lag behind and these represent a majority of the population in developing countries.

However, what these scholars overlooked was the fact it was not only the lack of information which was the sole contributor of underdevelopment in Third World countries. There were factors which communication alone could not solve. The major failure of the modernization theorists was their concentration on one factor alone with total disregard of other factors like trained human resource, marginalization by the developed nations and so on. Another weakness of the modernization paradigm is the lack of correlation between penetration of the mass media and increase in literacy levels. Without proper formal education literacy levels cannot improve, even if the media are there to disseminate information. If literacy levels are poor, it is difficult for people to understand the message or information made available to people through the mass media [2].

\section{Impact of Community Media in Kenya}

\section{Koch FM-Kenya}

George Maina, a news presenter, said in a media forum that Koch FM is a community radio based in a slum known as Korogocho in Nairobi which is inhabited by over 750,000 people. Koch FM was the first slum based community radio in Kenya whose example was followed by others such as Ghetto FM in Pumwani and Pamoja FM in Kibera slums. In a survey which covered Dandora, Mathare and Kayole, noted that the station is listened to by about 600,000 people daily. The station is run by about 42 volunteers, who work at slotted times during the day. Due to the nature of its surroundings, Koch FM broadcasts programmes which target the views and issues of the slum community. For example, issues of mugging and human rights violations are often reported by the listeners at the radio station making it run like a police station report office. Once they receive such reports and verify their validity, they present them on air for all to hear and take collective community actions. Other programmes in the community radio deal with advertising of jobs available in the community and the surrounding industries, ways of combating unemployment and idleness, the effects of drugs abuse, HIV/Aids, community health, human rights and many more.

However, they face challenges like they have not been able to develop a consistent programme schedule as many workers running the radio programmes are volunteers who drop out from the station when gainful employment is available elsewhere. Moreover, funding support of the programmes has been a problem. Also, the lack of presentation skills and capacities among the volunteers has been a problem. Many of the presenters are not adequately educated. It also aims at promoting participation in local and national socio-economic and political processes. 


\section{Kangema FM (106.5)}

Jean Fairbairn and Doreen Rukaria 2011 (OSIEA), Kangema FM (106.5) is to be found in a building on a hill slightly behind Gakira Market. Its premises are also home to staff members who have been trained to read the meters, check for evaporation and take rain measurements, which they are proud to do daily on behalf of Kenya Meteorogical Department. Kangema was not always a KMD station. It was initiated in 2008 by the local MP (who was also Minister of the Environment). The aim was to address environmental issues, in particular to help communities avoid land and mudslides which have killed many people in the area after heavy rains.

Funding came from the CDF. The KMD took the station over in 2009, upgrading equipment, restructuring governance bodies and recruiting also receives financial support for rent, equipment maintenance and salaries. Kangema FM broadcasts from 6 AM to midnight in Muran'ga and spilling over into Nyeri , Maragua and Kirinyaga. Farming is mostly agriculture, including maize, beans, sweet potatoes, vegetables, fruit and tea and coffee. There is also some livestock and dairy farming.

Over the past couple of years, crop yields and returns have been falling and poverty is increasing in the area. The weather has become more unpredictable, with later rains and sudden flooding that has caused major landslides, with loss of life. The KMD hopes to save lives and improve agricultural yields by providing an accurate and reliable weather service through Kangema FM, including discussion of seasonal changes and environmental issues and community needs, so that people can identify problems and solutions [3].

\section{Masinde Muliro University of Science and Technology FM (MMUST 103.9 FM)}

Jean Fairbairn and Doreen Rukaria 2011(OSIEA), Masinde Muliro (MMUST) 103.9 FM is a typical University community station. Run by the Masinde Muliro University of Science and Technology, just outside the town of Kakamega, in Western Province, provide for technical and communications students to do practicals. Because of its largely student audience, which comes from different parts of Kenya, the station broadcasts mostly in English and Kiswahili. Very few programmes are broadcast in Luhya, the language of the local community. Means it reaches outside the university gates to the thriving market and business community of Kakamega. Lecturers frequently bring mass communications students to the station as part of study tours and station staff members teach some classes. Students are encouraged to produce programmes under supervision at the station and the station may broadcast them, depending on quality.

Subjects, the station encourages are:

$\aleph$ Agricultural programmes

$\aleph$ Culture promotion programmes

$\aleph$ Gender issues

$\aleph$ Health, including HIV and AIDS

$\aleph$ Personal Development programmes, e.g. career choice and life skills

$\aleph$ Religious and Inspiring programmes income generating activity is agriculture and the station sometimes broadcasts programmes on agriculture, environmental issues and food security. Community participation is minimal, partly because the local community would communicate in Luhya.

\section{Mugambo Jwetu 102.3 FM}

Jean Fairbairn and Doreen Rukaria 2011 (OSIEA), Mugambo Jwetu 102.3 FM is located in Tigania East in the lower Eastern province of Kenya. The station, which also runs a Community Multimedia Centre, was founded by the Mugambo Jwetu Community Group, which was registered as a community-based group with the Ministry of Gender, Sports and Culture in 2005.

Tigania East is near the Nyambene Hills and is the home of the miraa (khat) plant. Miraa is exported mostly to Somalia and is the main income generating activity in the area. It is believed to be a contributor to the spread of HIV and AIDS in the area because of the links between wealth and prostitution. It is also seen as a cause of the high levels of illiteracy. Children drop out of school because they can earn good money from picking and packing miraa. Other issues in the area that the station hopes to address are high crime, high levels of violence against women, disintegration of families, female circumcision and early marriages. The local area MP was instrumental in starting the station and Mugambo Jwetu is housed in a building in the CDF compound, attached to the CDF offices [4].

\section{Oltoilo Le Maa 89.3 FM -Voice of the Maasai}

Oltoilo Le Maa FM (or Olmaa Ranet FM) is located in Suswa, a town in Narok District alongside the Nairobi Narok main road, which also leads to the world famous Maasai Mara e-station, is one of three community radio stations operating under the wing of the KMD, as part of its RANET-Kenya project. First initiated by the KMD in 2003, the station was tested, but failed to broadcast properly because of poor technical workmanship. Its objectives are:

$\aleph$ Inform and educate the community on weather and climate changes in our local language.

$\aleph$ Improve livelihoods of the local community, alleviating poverty through early warning on natural calamities for example, drought, famine, floods and environmental degradation, among others.

$\aleph$ Provide the latest information on market prices for crops and livestock.

$\aleph$ Inform and educate communities on the basis of human rights.

$\aleph$ Create awareness on HIV/AIDS.

$\aleph$ Sensitize the community on cultural injustices.

It promotes agriculture and livestock production by informing farmers about the weather and weather patterns well in advance. They purpose to broadcast programmes aimed at helping farmers cope with livestock diseases, like foot and mouth.

Staff members estimate that the station reaches around 56,000 people, in the Maa language enough, because many people who would benefit from programming cannot hear them.

Social issues which the station is committed to tackling include discriminatory and boys discontinue schooling after circumcision to become herdsmen, resulting in high levels of illiteracy.

The key challenge is electricity. A second challenge is space. The station currently rents its premises, a house with only three rooms. They say their third big challenge is mobilizing the community to use the station to its full potential as a development tool.

\section{Pamoja FM}

Jean Fairbairn and Doreen Rukaria 2011(OSIEA), Pamoja FM, 
broadcasting on $99.9 \mathrm{FM}$, is located on the top floor of an apartment block in Ayany, Kibera District of Nairobi Province. During the postelection violence in 2007/2008, Pamoja FM played an important role in lowering tension and restoring peace in Kibera by bringing representatives from different communities together for on-air discussion about their differences and about the effects of violence. Pamoja FM aims to take development efforts to a new level, by tackling ignorance and empowering the community to participate in their own is a Swahili word the importance of cooperation to overcome poverty, hunger, social hazards and in justices, gender violence, HIV and AIDS, climate change and community negativity and apathy [5].

\section{Serian 88.9 FM}

Jean Fairbairn and Doreen Rukaria 2011(OSIEA), Serian 88.9FM is situated $3 \mathrm{~km}$ from Maralal town in Samburu District. Serian FM went on air on 1st July, 2009, and covers a radius of $27 \mathrm{~km}$. The station is licensed to broadcast to a $50 \mathrm{~km}$ radius, but transmission capacity is currently too weak. The station seeks to promote the Samburu culture and address issues affecting the community namely:

$\aleph$ Animal Health and trading

ふ Female Genital Mutilation

\section{$\aleph$ HIV and AIDS}

$\aleph$ Trachoma, which is rampant as a result of flies. Flies are attracted because of the ways in which the community stores milk and blood, which are traditional foods.

$\aleph$ Peace and conflict resolution. Conflict is caused by cattle rustling by raiders armed with machine guns and rifles. At the time of our research, security was so bad that we could not visit the station.

$\aleph$ Education, especially for girls. Listenership is estimated at about 10,000 people, but numbers are inconsistent because of migration.

\section{Radio Maendeleo}

According to Fredrick Majiwa Station Manager, Bondo Community Multimedia Centre (Radio Maendeleo), Radio Maendeleo is a community radio based in Rarieda District in Ndori market. Radio Maendeleo officially went on air on July $31^{\text {st }}, 2007$. UNESCO bought the equipment for the radio and helped to train the volunteers in conjunction with Eco News Africa. The station addresses issues such as health, education, gender, business, paralegal issues, fishing industry and agriculture among others. The station at first experienced hostility from the community who perceived the station as a private station owned by the former MP of the constituency. Since it was viewed to be a private radio station for the former MP who was not in the popular party in the region, the radio was targeted for attacks [6].

\section{Radio Mang'elete}

This is a community radio station owned by 33 women groups but is currently off-air. It is situated at a small town called NTHONGONI, which is $14 \mathrm{~km}$ from Mtito-Andei town, $4 \mathrm{~km}$ from Chullu hills and 3 $\mathrm{km}$ from Tsavo West National park.

It has a coverage area of about $150 \mathrm{~km}$ radius and an audience of approximately 1 million people. $90 \%$ of its transmission is done in Kikamba, the local language and $10 \%$ in Kiswahili targeting nonkamba speakers in the area such as the Maasai and Taita and those living along Mombasa and Nairobi road.

Radio Mang'elete mainly focuses on programmes that enhance the well-being of the entire community regardless of their age, sex, religion, socio-economic status and politics. The local people claim that the community has changed greatly as evidenced in:

i. The marginalized group, i.e., women, disabled and children have got access to Information as well as given their views.

ii. The economic status of the people has improved as a result of educative programmes transmitted at the station.

iii. The health of the people has improved due to sensitization on common illness and the available treatments.

iv. It has proved to be the best tool for improving the social standards of the community.

v. The community is proud to be associated with the ownership of a radio station and they are always ready to contribute educative materials in programme production.

vi. The radio has provided a forum for discussion through live calling, SMS and debate.

\section{Ghetto FM}

Ghetto FM 99.9 was launched on 17th October, 2007. It is an offspring of one of the four pillars of the organization known as Slums Information Development and Resources Centers (SIDAREC). Other programmes covered by SIDAREC include Information Communication Technology (ICT) services, youth reproduction health, entrepreneurship and early childhood education.

Ghetto FM was mainly established to amplify the voice for the voiceless, seeks to better skills, eliminate stereotype and enhance a sense of belonging amongst individuals of the Ghettos. It is driven by a common desire and commitment to build an all-inclusive, people centered and development oriented information society where anyone and everyone can share and access information and knowledge.

Role of the station in presenting peace during and after the post-election violence in Kenya Programmes were encouraged and presented in a manner that the audience was made aware of where the election was and had taken place. The station contributed to the peace that was realized in Kamukunji constituency during this period Radio presenters were allocated duties in the slums to record and present messages of peace. It also appealed for the understanding and support for those evicted from their homes in the country and Kamukunji. There is confusion of names and conflict of interest with Ghetto Radio. Ghetto Radio is a commercial radio station currently Ghetoo FM is off-air.

\section{Programmes:}

1. Changamka: Dealing with current affairs and politics that affect the community.

2. Dau la Vijana: The name means the 'boat of the youth' and depicts about the life of the youngsters in the sea of life that is full of uncertainties. It mainly deals with issues of sexuality, entrepreneurship, unemployment, HIV/AIDS and STIs, among the youth.

3. Ghetto ICT: Seeks to educate the community on the importance of the Information, Communication and Technology. The Centre has a cybercafé, a library and video services.

4. Maisha ya Ghetto (Life in the Ghetto): Focuses on the day to day life of a slum dweller. It is meant to offer encouragement and hope. 
5. Afya ya mtoto (Children health): Educates on child nutrition and health; providing cheap and affordable tips to healthier living and common children diseases.

\section{Biashara na Mazingira: Business and environment.}

7. Ghetto Women: Focuses on the girl child from birth in the Ghetto to the time when she grows to become a Ghetto woman. Highlights trends of life and what it entails in the day to day life of a Ghetto woman [7].

\section{International Community Mediascape}

\section{Simli radio-Ghana}

In a study on Simli Radio on livelihood improvement of the people in the Tolon-Kumbungu and Savelugu-Nanton Districts of the Northern Region of Ghana it was established that Simli Radio has worked to improve awareness and knowledge of solutions to community development problems ranging from culture, rural development, education, hygiene and sanitation, agriculture to local governance. The station has been an appropriate medium that has facilitated an interface between duty bearers and rights holders. It has promoted small and medium enterprise development by creating market opportunities for Small and Medium Enterprise (SME) operators and consequently improved sales and incomes.The study found Simli Radio had been used to improve awareness and knowledge of solutions to community development problems within various sectors including culture, rural development, education, hygiene and sanitation, agriculture and local governance among rural people living in the Dagbani speaking districts in particular. There was increased enrolment in school through the School for Life (SfL) literacy programmes being broadcast on the station; reduced out-migration by young girls (Kayaayo) due to the station's enlightenment and an increased use of fertilizers by farmers. There has also been increased awareness on hygiene and sanitation issues in the sampled communities as well as enhanced social cohesion, manifesting itself in several ways including friendship and conflict reduction. More so, listeners have been able to broaden their horizon of knowledge through the opportunity provided to them by the radio in terms of broadcasting international news. On communication and information sharing, through its (Simli Radio) strategy of communal listenership, more than 100 communities had formed listeners clubs across the two administrative districts in the Northern Region of Ghana. They listen and are able to track programmes and make inputs as to what should be encouraged or changed. This promotes ownership and relevance of programmes to the people. Listeners identify themselves with the programmes and listeners clubs are a valid indicator of radio reception. This finding about Simli Radio finds support with the assertion of Sterling et al that Community Radio provides listeners with the voice with which to respond to programming and to create programming content. Radio Ndef Leng - Senegal Steve Buckley, Senegal and Radio Ndef Leng is operated by a Sérère cultural association. It broadcasts in 14 languages and is the most important radio service for the Sérère speaking community. For much of the day Radio Ndef Leng programming consists of an on-air dialogue among its listeners. Sometimes a topic is chosen for discussion while at other times the audience defines the conversation of the day. Listeners phone in through a call-center which assures that part of the cost of the call goes to sustaining the radio station. There is a constant queue of listeners waiting to speak. The role of the radio presenter is to act as a facilitator, to guide the discussion and to prevent abuse of the air time.

\section{Bush radio, radio Ndef Leng - Senegal}

Bush Radio which is acclaimed as the 'mother of community radio in Africa' began as a brief-case radio station in the 1980s in the Western Cape against a background of the apartheid regime [6]. A group of people known as CASET (Cassette Education Trust) started producing radio-type material on audio tapes containing information on community issues that were not allowed by the state media. These cassettes were distributed to people within the community in the Cape Flats. With the dawn of democracy into South Africa, Bush Radio was ready to transform itself from CASET into a full community radio station. According to the station manager, by 1998 the radio station had 2000 members with half of them willing to participate in the radio. Because of this, "Bush radio is essentially a training radio station. What this means is that more emphasis is put on developing the skills of potential broadcasters in the community." The station manager further stated that the station welcomes programme proposals from the community, NGOs and all interested parties. There is a programme committee that meets regularly to discuss the proposals, make recommendations and look at the financial possibilities of putting the programmes together. The themes broadcast by Bush radio include the importance of completing the tuberculosis treatment, HIV/AIDS, crime prevention, importance of education, teenage pregnancy, etc.

\section{XK FM radio-South Africa}

Thomas Bongani, XK FM, is a community radio station under the control of the South African national public broadcaster, the South African Broadcasting Corporation (SABC). It was granted a four year community sound broadcasting license by the Independent Communication Authority of South Africa (ICASA) in 1999 after many years of the two communities and their leaders rallying as a cohesive movement for the preservation of their languages, cultures and heritage as well as better living conditions. The purpose of granting this license to the! Xun and the Khwe and establishing XK FM was to create a platform that would preserve the two languages and respective cultural heritages of the! Xun and Khwe and provide a channel for development. It was viewed as a tool to provide better social services to the two communities, to alleviate poverty and to facilitate successful citizenship. Owing to the small size of the two communities and the lack of sustainable funding for XK FM, the radio station had to be established under the financial management and control of the SABC.

In 2000, XK FM broadcast live under the banner of the SABC for the first time from three large metal containers placed in Schmidt drift. It was given a frequency transmission footprint of a $50 \mathrm{~km}$ radius by SENTECH in accordance with the community broadcasting license requirements of the Broadcasting Act of 1999.

$\mathrm{XK}$ FM is seen by most of its management, programme and broadcasting staff and members of both communities as a community station that is theirs. Prior studies have revealed that actual SABC ownership notwithstanding, the locals claim ownership of the station because it is their people who are managing and working at the station, transmitting in their languages and voicing their stories, music and respective heritages However, Brilliant Mhlanga argues that XK FM operates more as a tool for manipulation by the ruling elite than as a facilitator of development. This is because to him, XK FM does not conform to the general typology of a community radio station, in its terms of ownership and community participation. For Mhlanga (2006, 85-89), XK FM is run more on the lines of a decentralized station of the public broadcaster with top-down approaches of management, production and communication with its control over 
ownership of the station. XK FM does not have a board of directors representative of the two communities or drawn from associated community organizations such as SASI and the CPA, the Sol Plaatje municipality or the government. Thus, the SABC controls decisions made on policies directed at XK FM, the station's objectives and the administration of finances and staff. As a community-targeted station financed and governed by the SABC, XK FM is required to follow the regulations, policies and objectives of the public broadcaster while also implementing ICASA-stipulated regulations, policies and objectives as a community radio station. This arguably creates a conflict of interest and crisis of identity within the station.

\section{Siyaya FM-South Africa}

Peter Mhagama Siyaya FM is the Cato Manor Community radio station which was officially launched on 1st July 2001. The name 'Siyaya' means 'we are getting there' or 'we are moving forward'. It was chosen during the planning stage because the community radio was to be regarded as a community mouth-piece which would encourage people 'to get there', to the dream of turning Cato Manor into 'a citywithin-a-city'. Cato Manor lies to the West of Central Durban. It is bordered by the Pavilion Shopping Centre and N3 freeway in the North, Sarnia Road in the South, Manor Gardens and the University of KwaZulu-Natal in the East and Westville Prison in the West. The history of the area has been characterized by racial, class and gender tension, violence and turbulence, on the one hand, but on the other hand, Cato Manor has also been a recipient of major development spending and has become an area of special interest on the part of a development organization.

Initially Siyaya FM was buying air time on Highway Radio, chosen because the two stations share the same audience and also because Highway Radio was found to be cheaper than other Durban stations when it comes to buying airtime. At first Siyaya FM was buying airtime on Highway Radio but later the two radio stations signed an agreement which allowed Siyaya FM to produce pre-recorded community related programmes only which would be aired on Highway Radio at no charge.

In 1993, this national coordination committee was formalized into the National Community Radio Forum and was mandated to serve the development-oriented community stations and would-be broadcasters based in disadvantaged communities all over South Africa (Teer-Tomaselli and de Villiers, 1998: 166). The programmes are heavily influenced by selected themes which the management of the radio station thinks are relevant to Cato Manor community. Initially there were three themes that were identified as relevant to Cato Manor community namely, Black Economic Empowerment (BEE), Heritage celebration and Summer Bridge Project. A 30-day Special Events License was obtained for each of these major themes.

\section{Jamaican community radio project}

The Jamaican Community radio Project was launched in 1979 with the aim of involving farmers in agricultural development. The station received its funding from USAID and was to operate for three years. It was soon discovered that the producer of agricultural programmes knew little about farming and was advised to start accompanying the researcher on village visits because an agricultural officer was dictating what was good for the farmers. Following this development, farmers' ideas formed the agenda for the agricultural programmes. The production team adopted colloquial Jamaican English which was the language that most farmers spoke and understood. An audience survey was conducted to find out the farmers' preferences. After the survey the station started broadcasting dramatized formats of local news in Jamaican English not only to make the news presentation more interesting, but also to attract more listeners. The station also started playing indigenous music for entertainment because it was the music that had an immediate appeal to the farmers. Lessons that were learnt from this radio project are that audience surveys are important in order "to get audience input in the formative stages of programme development." Thus, there was great involvement of the targeted audience in the production of content of the programmes.

When the USAID contract expired, the station manager, who had qualifications in acting and radio production was left to handle the finances. The project began experiencing financial hardships which forced the station manager to resign. Three years later, when the Jamaican government adopted a new media policy, the

Jamaican Community Radio station was turned into a commercial station [7].

\section{Radio Baha- Ecuador}

Radio Baha'i, a community station located in Otavalo, Ecuador was launched in 1977, the station aimed at promoting and maintaining the values, dignity and culture of rural Ecuadorians, promote basic education, the delivery of social services, and the distribution of development information; and served as a center for the exchange of local news and information. The station's strength lies in its use of Quichua, a local language in most of its programming and maintaining listener loyalty. It was able to do this through its daily news broadcasts. The local news broadcasts contain stories about lost children, livestock or property and also community activities. These stories are broadcast free of charge, thereby prompting many listeners to travel long distances to deliver their messages to the station and to interact with the station staff. Radio Nagercoil-India Radio Nagercoil was established in 1984 in rural Tamil Nadu, India to function as a mouthpiece of the local community. It was established as an affiliate of All India Radio (AIR). Most of this radio's programmes are field-based produced with the aid of producers who "conduct field participantobserver studies of the people and their needs, culture and lifestyles." The radio also arranges for access programmes with the help of local producers. Local artists, speakers and musicians are given air-time to perform or make a speech. The channel also serves as a two way channel of communication between development agencies and the local people. For example, the station helped settle a dispute between two rival fishing groups by bringing together all concerned groups and interviewing each group to give their side of the story. The views were then conveyed to the fisheries department which finally resolved the dispute. The involvement of government agencies and the bringing together of people to solve problems has been a major strength of this community radio station [2].

\section{Mahaweli community radio (MCR) - Sri Lanka}

Analyze Mahaweli Community Radio (MCR) in Sri Lanka. The radio station receives its financial assistance from UNESCO and DANIDA, and it went on-air in 1981 following the introduction of the accelerated Mahaweli Development Programme by the Sri Lankan government in 1977. The radio project was to be under, but independent of the Sri Lankan Broadcasting Corporation (SLBC) and it was introduced to encourage farmers to actively take part in the development process and to strengthen the rice improvement scheme.

In terms of community access and participation, people are 
involved in the planning, recording and editing of programmes. This is made possible because the production team carries out audience surveys first to study the social structure, demographics, economic levels and agricultural activities of a particular village.

Based on the material collected, the production team spends nights in selected villages to organize and record activities in which everyone participates. The materials recorded include dramas performed by the villagers, traditional music and interviews with local experts who offer information to farmers.

The programmes of the radio station also cover development information, agricultural news, irrigation methods, inland fishing, animal husbandry, health, nutrition and many more.

\section{Radio Angkringan- Indonesia}

Radio Angkringan, just outside Yogyakarta, Indonesia, in the village of Timbulharjo, there is a community owned and volunteer run radio station called Radio Angkringan. It is named after the informal pavement food stalls where people sit to eat, drink and talk - a kind of popular meeting space. Broadcasts are in the evenings because in daylight hours people are too busy working their living from the land. The station has just one computer with an audio bank of Indonesian music, together with microphones, a small mixing unit, a low power transmitter and antenna. This, together with the voices of volunteers, local listeners and guests, provides the broadcast service. The volunteers at Radio Angkringan gather news from the Internet but connectivity is unreliable and expensive. They have acquired a motorcycle and a portable recording kit so they can now make field recordings in the neighbouring local villages.

\section{Valley free radio -USA}

Valley Free Radio came about due to the Johnny Appleseed travels of Prometheus Radio Project's Pete Tridish. In 1999, he took to the road spreading the word that there was an opportunity for community organizations to apply for low power, noncommercial radio licenses. He met another local, Ed Russell, through Prometheus and together, they called a town meeting, inviting interested parties to talk about the idea of a community radio station in Northampton, explicitly stating that they intended it to be progressive station.

The group that formed that night as the Valley Free Radio Project made plans to create an Internet list serve and form committees to begin tackling the various components of the application. The group created the following mission statement to guide its efforts: Valley Free Radio is an independent, non-commercial community based and volunteer-run radio station for the Greater Northampton area. We seek to educate, inspire and entertain through programming that reflects the diversity of the local community. We seek to provide a space for media access and education, placing equipment, skills and critical tools in the hands of the community. We aim to serve with particular regard for those overlooked or under-represented by other media and to provide a form for the exchange of cultural and intellectual idea and music.

Tridish emphasizes not losing track of the big picture, that of creating "a culture of kindness and gentleness and humor" (2009). He points to stations such as Radio Free Nashville, WRFN 98.9 FM, which have focused on being inclusive, rather than on specific politics, when recruiting volunteers for the station; a major problem facing Valley Free Radio. Tridish notes that by being a community resource and making it a priority to do community outreach to underrepresented groups, Radio Free Nashville has succeeded in side stepping many of the issues VFR continues to face. Tridish provides other examples of low power stations that have had race as an important piece of their mission. Two low power stations (in Florida and Oregon), while admittedly homogeneous organizations made up primarily of Latinos, provide labor information that has potential to make a difference in the lives of migrant workers. WCIW 107.9 FM, started by the union for Immokolee Migrant Workers in Immokolee, Florida, is an important example of a radio station reaching out to and organizing within its community. Another low power station, KRBS 107.9 FM, also known as Radio Bird Street in Oroville, California, serves an urban community where the only other station in town is owned by Clear Channel, which actually moved the physical station out of town, and replaced it with automation. The low power station has provided a catalyst for revitalizing the downtown area by giving people a community project to work on together. The missions of these radio stations demonstrate that advocating for anti-racism does not have to create internal divisions. They have all focused their attention on projects that help the community organize and proactively engage with the station.

\section{Conclusions}

Community stations that try to remain a-political, non-partisan and all inclusive, especially, in conflict prone areas have greater impact in delivery of services. Effective management and leadership are critical in ensuring the performance of radio stations. Leadership is key for mobilizing resources, directing programme activities and evaluation of programme impact. The stations have also been largely used as a tool for integrated rural development. The stations have been operated as a social responsibility of providing community news bulletins, current affairs, sporting, culture and health programmes. There is a very high degree of listener participation in the programmes and the rural audience likes to hear themselves and their neighbors on radio. However, in Kenya they face stiff competition from their wellfunded commercial counterparts. In terms of ownership community members feel they are part of the ownership because their suggestions or recommendations have been heeded to by staff of the stations. They also participate in the programmes by way of making announcements, call-ins, SMS, electing management boards and advertisement.

\section{Recommendations}

From the countries in which community broadcasting is successfully established, some common characteristics of good practice can be quickly identified.

1. There should be clear and explicit recognition of community broadcasting as a distinct sector.

2. There should be a straightforward and transparent process for the allocation of spectrum and the licensing of community broadcasting.

3. The regulatory framework for community broadcasting should have regard to the sustainability and resourcing of the sector. Community broadcasters should be encouraged to develop economic support from within their own community but assistance should also be provided through independently administered public funding mechanisms.

4. Reform of the legal and regulatory environment should be supported by capacity building to assure the sustainability of community broadcasting initiatives. This includes training in production and management, technical advice and guidance, 
investment in social and development content and support for country level associations that can speak on behalf of community broadcasters and provide a forum for sharing of experience and best practice.

5. Innovative use of mixed media/technology: Community Broadcasting needs to strategically combine old and new communication technologies and develop mixed media models. Some examples below illustrate the point.

6. Strengthen relationship between community and public broadcasting sectors: There needs to be more engagement between the community broadcasting and public broadcasting sectors.

7. Engage with academia: There needs to be more research and impact assessment studies that track and evaluate performance.

8. Strengthen Networking: Even while community radio may be a recent entrant in some countries in Asia Pacific, there needs to be a greater emphasis on networking both at the country and regional levels. Networks comprising community radio practitioners, advocates and community media production groups at the country and regional are required to strengthen the case for legal reform, technology access and fund raising. They are also valuable mechanisms for content sharing and dissemination, awareness and capacity building.

9. Governments should develop a clear roadmap, including budgets, towards the deadline of digital migration in transparent consultation with all stakeholders - broadcasters, signal distributors.

\section{References}

1. Mhagama PM (2004) The Role of Community Media in Development: A Case Study of the Cato Manor Development Project.

2. Allen T, Seaton J (1999) The Media Of Conflict: War Reporting and Representations of Ethnic Violence, Zed Books, London.

3. Anderson D (2008) Kenya's Agony. Royal African Society.

4. Anderson D (2008) Kenya on the Brink. Prospect.

5. Anderson D (2008) How Violence Affected Kenya's Democracy.

6. Balch J (1991) Jabulani! Freedom of the Airwaves. African-European Institute Netherlands.

7. Bosch TE (2006) Radio as an Instrument of Protest: The History of Bush Radio Journal of Radio Studies 13: 249-265. 